\title{
Construction and practical application of hybrid statistically- determined models of multistage mechanical systems
}

\author{
A. Goroshko*, V. Royzman*, J. Pietraszek** \\ *Khmelnytskyi National University, Instytutska 11, 29016 Khmelnytskyi, Ukraine, E-mail: iftomm@ukr.net \\ **Cracow University of Technology, Kraków, Poland, E-mail: pmpietra@gmail.com \\ cross'ref http://dx.doi.org/10.5755/j01.mech.20.5.8221
}

\section{Introduction}

It is possible to construct a relatively simple structural model of complex mechanical systems, adequate to real object by identifying such primary factors which have a significant impact on the output characteristics of the object material, simplifying the model by discarding unimportant factors. Meanwhile, it is disputable whether the criterion of substantiality of the primary factors considered is valid.

Although methods of parametric sensitivity theory $[1,2]$ allow to evaluate the degree of influence of each of the primary factors on baseline characteristics of the object, it does not provide an answer to this question.

At the same active methods of design of experiments (DOE) for building statistical models provided a reasonable opportunity to screen out non-essential primary factors [3]. However, DOE can be performed not only on the real object, but also on its determined mathematical model. In this case, using the principles of DOE will also enable the specified determined model simplification.

For this use of DOE as a method of building statistical models to analyze and simplify deterministic models demonstrates the close relationship of these species examined of structural model of mechanical systems and processes for their manufacture. Indeed, the abovementioned division of mathematical models is rather relative, since both approaches are organically interrelated and complementary. Thus, clarification and authentication of determined models should be implemented by the statistical data of experiments on the real object or physical models, and statistical models - should be constructed with regard to well-known theoretical relationships. In addition, the identification of reliable statistical distribution models of structural model of complex technical products parameters that can reasonably judge the actual spread of values, increases the effectiveness of the use of mathematical

The following describes some of the ways that reduce the complexity and duration of the operations that are necessary to implement a full factorial design to create mathematical models of many cascading of structural model of mechanical systems. This can be achieved by constructing hybrid statistically determined models, and through informed choice of the minimum number of $n$ overlap each experiment with the given reliability $P$.

\section{Problem statement}

Let's consider an object that contains such independent cascades where the variation of the primary factors of any of them changes the output characteristics of this cascade only. The problem through the use of DOE simulated output characteristic of all products in cases where mutual influence cascades is known in advance. Thus we consider multistage products, whose design and traditional manufacturing techniques cannot and (or) does not provide for an interim control of individual stages. At the same time, the possible values of the simulated measurement function for an arbitrary set of values of the primary factors of all cascades.

\section{The results of theoretical studies}

Further, we'll provide the solution method of the considered problem.

The desired model can be represented as a known function:

$$
y=f\left(\varphi_{1}, \varphi_{2}, \ldots, \varphi_{k}\right), \varphi \in \boldsymbol{R}^{k},
$$

where

$$
\varphi_{i}=\varphi_{i}\left(x_{i 1}, x_{i 2}, \ldots, x_{i l_{i}}\right), i=1,2, \ldots, k
$$

are unknown functions which model $i$-th cascade, and $x_{i j}$ is coded primary factors.

We denote the set of factors $\left\{x_{i 1}, x_{i 2}, \ldots, x_{i l_{i}}\right\}$ vector $\boldsymbol{x}_{i}, i=1,2, \ldots, k$, then relationship (1) and (2) takes the form of

$$
y=f\left(\varphi_{1}\left(x_{1}\right), \varphi_{2}\left(x_{2}\right), \ldots, \varphi_{k}\left(x_{k}\right)\right)
$$

Thus, the task is to construct a method of DOE polynomial representation of the function (3), specified by the primary factors. The method for solution of this problem is suggested, which is based on modeling the dependence of output of the product of the primary factors of each stage separately (the value of the primary factors other stages at this time are fixed at a certain level) and subsequently combining them within a common object model in accordance with the known theoretical dependence.

To implement the proposed methods it is necessary to carry out the following sequence of actions.

Formation at the beginning $k$ support functions:

$$
\begin{aligned}
& y_{i}=f_{i}\left(\varphi_{10}, \varphi_{20}, \ldots, \varphi_{(i-1) 0}, \varphi_{i}\left(\boldsymbol{x}_{i}\right), \varphi_{(i+1) 0}, \ldots, \varphi_{k 0}\right), \\
& i=1,2, \ldots, k,
\end{aligned}
$$


where $\varphi_{j 0}$ is fixed but unknown value function $\varphi_{j}$ the unknown fixed set of primary factors $\boldsymbol{x}_{j 0}$.

Applying $k$ times full factorial design, we obtain the polynomial representation of each function $y_{i}$ in the form:

$$
y_{i}=b_{0}+\sum_{i=1}^{l_{i}} b_{i} x_{i}+\sum_{i, j} b_{i j} x_{i} x_{j}+\ldots
$$

where $b_{0}, b_{i}, b_{i j}$ are coefficients of the model, written in coded values of factors. Thus, by implementing $2^{l_{1}}+2^{l_{2}}+\ldots+2^{l_{k}}$ experiments determine the dependence $y_{i}=y_{i}\left(\boldsymbol{x}_{i}\right)$. Next, substituting the obtained function alternately to the left side (4), expression all $\varphi_{i}\left(\boldsymbol{x}_{i}\right)$ through $y_{i}\left(\boldsymbol{x}_{i}\right)$ and $k-1$ constant $\varphi_{j 0}$ :

$\left\{\begin{array}{l}y_{i}\left(\boldsymbol{x}_{i 0}\right)=f_{i}\left(\varphi_{10}, \varphi_{20}, \ldots, \varphi_{(i-1) 0}, \varphi_{i}\left(\boldsymbol{x}_{i}\right), \varphi_{(i+1) 0}, \ldots, \varphi_{k 0}\right), \\ \varphi_{i}\left(\boldsymbol{x}_{i}\right)=g_{i}\left[\begin{array}{l}y_{i}\left(\boldsymbol{x}_{i}\right), \varphi_{10}, \varphi_{20}, \ldots, \varphi_{(i-1) 0}, \varphi_{i}\left(\boldsymbol{x}_{i}\right), \\ \varphi_{(i+1) 0}, \ldots, \varphi_{k 0}\end{array}\right]\end{array}\right.$

Measuring the value of simulated output characteristics for fixed values of the primary factors that record value:

$$
\begin{aligned}
& y_{0}=f\left[\varphi_{1}\left(\boldsymbol{x}_{10}\right), \varphi_{2}\left(\boldsymbol{x}_{20}\right), \varphi_{3}\left(\boldsymbol{x}_{30}\right), \ldots, \varphi_{k}\left(\boldsymbol{x}_{k 0}\right)\right]= \\
& =f\left(\varphi_{10}, \varphi_{20}, \ldots, \varphi_{k 0}\right) .
\end{aligned}
$$

As can be seen from
$y_{i}\left(\boldsymbol{x}_{i 0}\right)=f\left(\varphi_{10}, \varphi_{20}, \ldots, \varphi_{(i-1) 0}, \varphi_{i}, \varphi_{(i+1) 0}, \ldots, \varphi_{k 0}\right)=y_{0}$.

Substituting Eq. (6) by Eq. (1), after transformation we obtain the function $y$, depends now on the primary factors $\boldsymbol{x}_{1}, \boldsymbol{x}_{2}, \ldots, \boldsymbol{x}_{k}$ fixed and unknown numbers $\varphi_{10}, \varphi_{20}, \ldots, \varphi_{k 0}$, i.e.:

$$
y=\psi\left(\boldsymbol{x}_{1}, \boldsymbol{x}_{2}, \ldots, \boldsymbol{x}_{k}, \varphi_{10}, \varphi_{20}, \ldots, \varphi_{k 0}\right) .
$$

Because $\boldsymbol{x}_{i}=\boldsymbol{x}_{i 0}, i=1,2, \ldots, k$ occurs $y=y_{0}$, it is true inequality:

$$
y_{0}=\psi\left(\boldsymbol{x}_{10}, \boldsymbol{x}_{20}, \ldots, \boldsymbol{x}_{k 0}, \varphi_{10}, \varphi_{20}, \ldots, \varphi_{k 0}\right),
$$

that allows you to opt in Eq. (8) from unknown $\varphi_{i 0}$, expressing them through the measured value $y_{0}$, and thereby obtain the desired appearance modeling function.

At the same time, necessary for the implementation of the described methods the number of experiments $2^{l_{1}}+2^{l_{2}}+\ldots+2^{l_{k}}$ significantly smaller number of experiments $2^{l_{1}+l_{2}+\ldots+l_{k}}$, required to implement the standard full factorial design.

For the informed choice of the minimum number of repetitions of each experiment by measuring the value of the function $y$ will use the method of confidence intervals for assessing the expected value and standard deviation of normally distributed random variables with given probability $P_{1}, P_{2}$.

It is easy to show that the reliability $P_{1}, P_{2}$ number $n$ can be found from the expression $n=T^{2} \sigma^{2}(1-q)^{2} / \delta^{2}$, where $\sigma$ is selective standard deviation is corrected, $T$ is such value of argument of function of Laplace $\Phi(T)$, at which $\Phi(T)=P_{1} / 2, q$ is number which is determined from a table [4], $\delta$ is set number that determines possible deviation of mean value of the realized experiments from the truth value of measuring size.

Thus, the offered method of construction of the hybrid statistically-determined models of multistage objects, that allows to form statistical models taking into account the known theoretical dependences, gives the considerable winning in an amount experiments at raising of DOE in comparing to the construction of clean statistical models.

This circumstance acquires the special importance in those cases, when amount of primary structurallytechnological factors that influence on the value of initial description of object and amount of cascades great enough, and also, when quality of work of good is characterized not one, but by a few initial parameters.

\section{Implementation outcomes of the method}

The method of creation of the hybrid statisticallydetermined models was applied for providing the power stability of initial signal of microwave-range device. The signal generated by mechanical factors.

The device being examined is the transmitter of airplane defendant (AD). AD SO-69 (Fig. 1) is used to work with the air traffic control systems and installed on civil and military aircraft, such as for example the MiG-23, MiG-25, MiG-27, MiG-29, MiG-31, Tu -142, Tu-95, Yak40, L-410, AN-26 and transport helicopter Mi-26. In its manufacture, testing and operation there were multiple cases, when $\mathrm{AD}$ were accepted during initial tests during that correspondence of all initial descriptions was set to the technical requirements, and farther in exploitation there were refuses of these wares on completion of some time. The analysis of such refuses showed that most percent of non-fulfillment $(23.7 \%)$ AD the functional setting took place in a kind the impermissible on technical requirements decline of power of initial high-frequency signal.
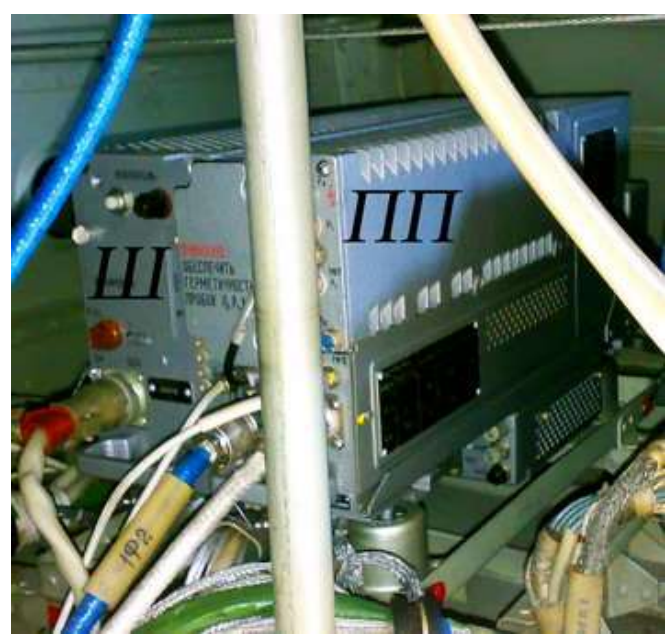

Fig. 1 Appearance of the AD SO-69 
Previous experiments, carried out by the manufacturing plant, showed that further treatment of electric parameters of defendant cannot result in stabilizing the size of power of its outgoing high-frequency signal, as these parameters on the basis of existent element base are wellproven to some optimal values. However, the indicated power is formed under the action of some primary factors of mechanical nature.

Thus, we put task to identify primary factors of mechanical nature that influence on the size of power of initial high-frequency $\mathrm{AD}$ signal and to find the great number of values of these factors that provide implementation of technical requirements on this initial description during all term of exploitation.

\section{Construction of mathematical model of assembly of} AD

Power of initial high-frequency signal is formed in the transceiver of basic block of SO-69, and more precisely in intended for generating of high-frequency impulses in a decimetric range generator of microwave transmitter.

Microwave oscillator contains two independent cascades. The first cascade is an oscillator (master clock MC) second - power-amplifier (PA). Thus it is known that power of weekend of high-frequency signal $U$ appears as a product of two functions $U=\varphi_{1} \cdot \varphi_{2}$ that design each of cascades of $\mathrm{MC}\left(\varphi_{1}\right)$ and $\mathrm{PA}\left(\varphi_{2}\right)$, i.e.:

$$
U=\varphi_{1} \varphi_{2}
$$

Thus construction and technologies of stowage of defendant are not envisaged by intermediate control of these initial descriptions of separate cascades. Measuring of values of initial description of generator is possible only at the arbitrary sets of values of primary factors both MC and PA. Taking into account such multistageness of microwave oscillator for the design of power $U$ was used described higher method of construction of the hybrid statistically-determined models.

Will consider application of the worked out method for the design of work of microwave generator, for that a transmission function looks like Eq. (9), where, $\varphi_{1}(\boldsymbol{x})$, $\varphi_{2}(\boldsymbol{x})$ are unknown functions that design $\mathrm{MC}$ and PA accordingly. Then the measured value of the designed power equals at some fixed values of primary factors of $M C\left(x_{10}\right)$ and $P A\left(x_{20}\right)$ :

$$
U_{0}=\varphi_{10} \varphi_{20},
$$

where $\varphi_{i 0}=\varphi_{i}\left(\boldsymbol{x}_{i 0}\right), i=1,2$ is fixed but unknown value function $\varphi_{i}$.

Will form auxiliary functions:

$$
U_{1}=\varphi_{1}\left(x_{1}\right) \varphi_{20}, U_{2}=\varphi_{10} \varphi_{2}\left(x_{2}\right)
$$

from that

$$
\varphi_{1}\left(x_{1}\right)=U_{1}\left(x_{1}\right) / \varphi_{20}, \varphi_{2}\left(x_{2}\right)=U_{2}\left(x_{2}\right) / \varphi_{10} .
$$

Putting Eq. (12) in (9), will get $U=U_{1}\left(\mathbf{x}_{1}\right) \cdot U_{2}\left(\mathbf{x}_{2}\right) /\left(\varphi_{10} \cdot \varphi_{20}\right)$, where with taking Eq. (10) into account find:

$$
U=U_{1}\left(x_{1}\right) U_{2}\left(x_{2}\right) / U_{0}
$$

To get the statistically-determined model of kind Eq. (13) it is necessary to build polynomial models for functions $U_{i}\left(\boldsymbol{x}_{i}\right), i=1,2$ by realization $2^{l_{1}}+2^{l_{2}}$ of experiments on the chart of full factorial design $\left(l_{1}, l_{2}\right.$ are amount of primary factors for MC and PA accordingly). To that end it was first of all necessary to define those primary factors of $\mathrm{MC}$ and $\mathrm{PA}$, that must be taken into account in these models.

On the basis of expert survey of specialists who have experience in previous research of defendant construction and their assembly technology, it was found that the following parameters of details and knots of each of the cascades of oscillator transmitter can significantly influence on initial description $U$ - power of initial highfrequency signal.

Parameters of details and knots of $\mathrm{MC}$ : pressing force of the anode plug to the anode collet $q_{1} \cdot 10^{2}, \mathrm{~N}$; body diameter cathode-grid circuit $q_{2} \cdot 10^{-3}, \mathrm{~m}$; diameter glass cathode-grid circuit $\cdot 10^{-3}, \mathrm{~m}$; arithmetic average roughness glass cathode-grid circuit $q_{4} \cdot 10^{-6}$, m; pressing force of the large plunger $q_{5} \cdot 10^{2}, \mathrm{~N}$; the arithmetic mean deviation of the anode surface profile case circuit $q_{6} \cdot 10^{-6}, \mathrm{~m}$.

Parameters of details and knots of PA: diameter of glass cathode-grid circuit $Q_{1} \cdot 10^{-3}, \mathrm{~m}$; diameter of body cathode-grid circuit $Q_{2} \cdot 10^{-3}, \mathrm{~m}$; the arithmetic mean deviation of body surface profile of the anode circuit $Q_{3} \cdot 10^{-6}, \mathrm{~m}$; pressing force of the large plunger to the wall circuit $Q_{4} \cdot 10^{-2}, \mathrm{~N}$.

Farther in correspondence with worked out before by the method of construction of the hybrid statisticallydetermined model full factorial design was conducted, as a result of that expression is got for power through absolute variables:

$$
\begin{aligned}
& U=\left(-622.537+0.0094 q_{2}+1651.4286 q_{3}+\right. \\
& \left.+3643.286 q_{4}+49.06 q_{5}+351.4839 \cdot 10^{6} q_{6}\right) \times \\
& \times\left(-46.9037-802.8571 Q_{1}+586.5306 Q_{2}+\right. \\
& +2780816.33 Q_{3}+0.2277 Q_{4}-0,0152 \cdot 10^{-5} \times \\
& \left.\times\left(Q_{1}-0.03201\right)\left(Q_{4}-6\right)\right) .
\end{aligned}
$$

\section{Identification, analysis and ways of removal of influence of basic destabilizing primary factors}

Undertaken studies educed two priority factors that more substantial in all influence on the size of power of initial high-frequency signal of AD: AV arithmetic rejections of profile of surface of corps anodic to the contour and effort of pinning of great плунжера to the wall to the contour.

In order to study the possibility of change in the values of these factors in the process of exploitation and 
their destabilizing influence on the size of initial power conference of specialists on the manufacturing plant was held, where the following statements were made.

In the microwave-range endovibrators are used as oscillating systems where the transitional resistance of contacts of piston influences with the corps of resonator (Fig. 2) and with an anodic collet has a significant impact on the power. For providing of reliable contact it is necessary to have an internal surface of corps of resonator and external - anodic collet, enough high class of cleanness. However at the frequent tuning to the contour of resonator there is a heterogeneous wear of surface of contacts through the wipe of layer of silver, that covered plungers, that results in large variation of size of transitional resistance of contacts on length of their moving. The considerable rejections of electric parameters of resonator take place from it, in particular, initial power in the process of exploitation.

Thus, it was set that priority factors are considered and can destabilize the size of the indicated power. Research of possibility of support of values of the indicated factors at certain level during all term of exploitation showed that for the first from them implementation of such requirement was arrived at difficult and expensive, and adjusting of effort of pinning of large plunger to the wall of corps in general is not envisaged in a construction. In addition, even providing of the indicated requirements does not remove the wipe of thin level of silver on the surface of плунжера. In this connection further measures from providing of the indicated requirements on the considered destabilizing factors were confessed by ineffective, and was made decision about the necessity of revision of $\mathrm{AD}$ construction.

The construction of resonator was simplified by introduction of dielectric retort (Fig. 3), dielectric basis and silver segments, as a necessity of centring of piston falls off at the use of dielectric glass, requirements go down to the class of exactness of making of metallic retort and corps of resonator a surface, and the exception of direct contact of piston with the corps of resonator allows to bring down requirements to the cleanness of internal surface of corps of resonator and metallic glass. Thus, in the new pin-noncontact construction of $\mathrm{AD}$ it was succeeded to remove destabilizing factors that influence on the size of power of weekend high-frequency.

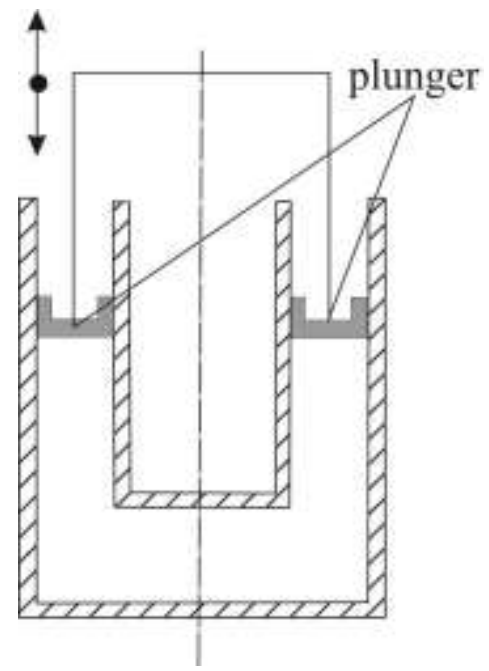

Fig. 2 Design of the cavity resonator

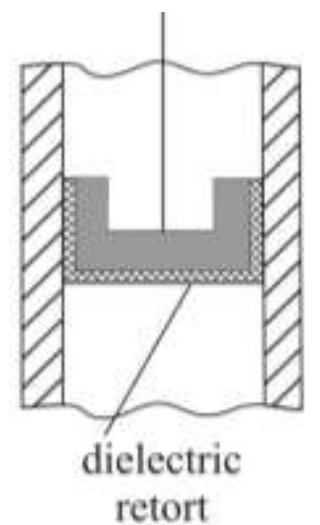

Fig. 3 Dielectric retort in a modified structure of the cavity resonator

For the modified construction of $\mathrm{AD}$ the hybrid statistically-determined model was also built:

$$
\begin{aligned}
& U=\left(8.858+0.109 q_{1}+27 \cdot 10^{3} q_{2}\right) \times \\
& \times\left(22509.043+3.12 Q_{1}+124.857 Q_{2}-812 \cdot 10^{3} Q_{1}\right) .
\end{aligned}
$$

The set dependences of power of initial highfrequency signal on the primary factors of defendant it is allowed to put plural reverse problem of determination of such admittances on these factors, at that implementation of condition would be provided on the considered initial description:

$$
U \geq U_{0},
$$

where $U_{0}$ is minimum value of power, that answers requirements to the technical requirements.

The considered problem can be set forth as follows. At the set nominal values of primary factors $\boldsymbol{x}_{0}=\left\{q_{20}, q_{40}, Q_{10}, Q_{20}, Q_{30}\right\}$ it is necessary to define such their possible rejections $\delta_{i}, i=1,2, \ldots, 5$ from basic values, that in the got parallelepiped $x_{i 0}-\delta_{i} / 2 \leq x_{i} \leq x_{i 0}+\delta_{i} / 2$ a condition (14) was executed on initial description.

As coming from reasoning of economy admittances it is desirable maximally to extend on all parameters, then the considered problem is a multicriterion, and the plural of criteria of part can be set forth in a kind

$$
F_{i}=-\delta_{i} \rightarrow \min , i=1,2, \ldots, 5 .
$$

For erection of this multicriterion problem to the onecriterion linear convolution of criteria of kind was used $\tilde{F}=\sum_{i=1}^{5} c_{i} \delta_{i} \rightarrow \max [5,6]$, where $c_{i} \geq 0, \sum_{i=1}^{5} c_{i}=1$ is rationed positive numbers that is determined from the productive or economic reasoning.

Thus, a problem is taken to determination of such values of admittances $\delta_{i}, i=1,2, \ldots, 5$, that achieves the objective function maximum $\tilde{F}$ on condition of implementation of limits on the primary factors taken from technical requirements and $\mathrm{AD}$ output description. Limitations were set by the set of inequalities (Table). 
For the new construction of $\mathrm{AD}$ determination of admittances was conducted on the primary factors of defendant, the basic values of that are driven to the Table.

The values of primary factors of AD are got at $\delta_{i}$, that maximize a function $\tilde{F}$ for $U_{0}=600 \mathrm{BT}$, driven to the Table.

Table

Values of the primary factors and constraints in the optimization problem

\begin{tabular}{|c|c|c|}
\hline $\begin{array}{c}\text { A limit is on } \\
\text { primary factors } \\
\text { and initial descrip- } \\
\text { tion of } \mathrm{AD}\end{array}$ & \multicolumn{2}{|c|}{ Value of primary factors of AD } \\
\hline$U \geq 600$ & Nominal & Optimal \\
\hline $50 \leq q_{1} \leq 450$ & $q_{20}=25010^{2}, \mathrm{~N}$ & $211 \leq q_{1} \leq 289$ \\
\hline $5 \cdot 10^{-6} \leq q_{4} \leq 2 \cdot 10^{-5}$ & $q_{40}=6.2510^{-6}, \mathrm{~m}$ & $6.25 \cdot 10^{-} 6 \leq q_{4} \leq 2 \cdot 10^{-5}$ \\
\hline $0.5 \leq Q_{1} \leq 4.5$ & $Q_{10}=2.50 \mathrm{~N}$ & $0.5 \leq Q_{1} \leq 4.5$ \\
\hline $0.33 \leq Q_{2} \leq 0.033$ & $Q_{20}=0.33065 \mathrm{~m}$ & $0.0330 \leq Q_{2} \leq 0.0331$ \\
\hline $0.0320 \leq Q_{3} \leq 0.032$ & $Q_{30}=0.03201 \mathrm{~m}$ & $0.03191 \leq Q_{3} \leq 0.03209$ \\
\hline
\end{tabular}

\section{Conclusions}

1. Developed a method for constructing a hybrid statistical and deterministic models of multistage structurally complex of mechanical systems, which can reduce the amount of experimental research. The surgical creation of a statistically-determined model to determine reasonable assumptions on the value of the primary structural and technological factors of a stabilization of output parameters to set limits, achieved the study of functions of several variables obtained from a known mathematical methods.

2. Constructed hybrid statistical-deterministic model of power output high-frequency signal of AD under primary factors of mechanical nature. Identified priority factors that destabilize the value of output.

3. Defined tolerances for primary factors of $A D$ in which compliance is guaranteed power output highfrequency signal with specifications

\section{References}

1. Sensitivity theory and its application // Problems of Cybernetics / By Society. Ed. RM Yusupov. M.: Communications, 1977. Issue. 23. - 188C.

2. Kofanov Y.N, Shalumov A.S, Zhuravskii V.G, Goldin V.V. 2000. Mathematical Modeling Of Electronic Means in Mechanical Actions. Moscow: Radio and communication, - 226p. (in Russian).

3. Johnson, N.L., Leone, F.C. 1977. Statistics and Experimental Design: in Engineering and the Physical Science. John Wiley. 490p.

4. Wentzel, E.S. 1969. Probability theory [Russian translation]. Moscow: Nauka. 576p.
5. Nakayama, H., Yun, Y., Yoon, M. 2009. Sequential Approximate Multiobjective Optimization Using Computational Intelligence (Vector Optimization). Springer, 197p.

6. Zitzler E. 1999. Evolutionary algorithms for multiobjective optimization: Methods and applications. Ithaca: Shaker 63. 134p.

\section{A. Goroshko, V. Royzman, J. Pietraszek}

\section{HIBRIDINIŲ STATISTIŠKAI APIBRĖŽTŲ MODELIŲ DAUGIAPAKOPĖSE MECHANINÉSE SISTEMOSE KŪRIMAS IR PRAKTINIS TAIKYMAS}

R e z i u m è

Straipsnyje pateikiamas hibridinių statistiškai apibrèžtų modelių sukūrimo metodas taikomas struktūriškai sudètingoms mechaninèms sistemoms. Toks metodas naudoja aktyvų planuojamą eksperimentą, leidžia žymiai sumažinti reikiamų eksperimentinių tyrimų kiekį. Darbe pateiktas sukurtas hibridinis statistiškai apibréžtos mechaninès sistemos modelis, užtikrinantis lèktuvo atsakiklio signalo galią. Buvo nustatyti prioritetiniai mechaninio pobūdžio veiksniai, kurie destabilizuoja išèjimo signalo galios lygị. Darbe išspręstas atvirkštinis uždavinys nustatant leidžiamas veiksnių reikšmes, kurios ịtakoja galios signalo lygi užduotų techninių sąlygų ribose.

\section{A. Goroshko, V. Royzman, J. Pietraszek}

\section{CONSTRUCTION AND PRACTICAL APPLICATION OF HYBRID STATISTICALLY-DETERMINED MOD- ELS OF MULTISTAGE STRUCTURALLY COMPLEX ENGINEERING SYSTEMS}

S u m m a r y

The paper proposes a method of creating a hybrid statistically-determined models for structurally complex of mechanical systems. The method uses an active planned experiment, but it can significantly reduce the amount of experimental research. Hybrid statistically-determined model of aircraft defendant signal power was created. Priority factors of mechanical nature destabilizing the output power level were identified. The study solved multiple inverse problem of determining the permissible values of these factors, in which the signal power is within specifications.

Keywords: modeling, mechanical systems, design of experiments, statistically-determined models, aircraft responder.
Received June 17, 2014 Accepted October 15, 2014 